\title{
A COMPARATIVE STUDY OF T-BEAM BRIDGES FOR VARYING SPAN LENGTHS
}

\author{
Sandesh Upadhyaya K. ${ }^{1}$, F. Sahaya Sachin ${ }^{2}$ \\ ${ }^{1}$ Assistant Professor, Department of Civil Engineering, Manipal Institute of Technology, Manipal, Karnataka, India \\ ${ }^{2}$ U.G. Student, Department of Civil Engineering, Manipal Institute of Technology, Manipal, Karnataka, India
}

\begin{abstract}
T-beam bridges are one of the most commonly used type of bridge and hence it is necessary to constantly study, update analysis techniques and design methodology. Structurally they are simple to construct and maintain. Hence they are preferred over other types of bridges when it comes to providing connectivity within short distances. The aim of our study was to determine the variation and suitability of two different configurations of these bridges, namely ordinary deck slab supported on girders and Tbeam configuration of deck slab. In this study we have considered span lengths of 20m, $24 \mathrm{~m}$ and $28 \mathrm{~m}$. The deck slab has been conventionally analysed for IRC class AA loading using Courbon's method. The process was made faster by formulating excel sheets for conventional design which gives maximum Bending Moment and Shear Force values arising due to dead load and live load for class AA wheeled vehicle. This study also takes into account all other components of a T-beam bridge such as cantilever slab, girders and cross beams. A complete FEM analysis of T-beam bridge with ordinary deck slab supported on girders was performed.FEM analysis was validated conventionally using Courbon's Method.FEM analysis for both the configurations of Tbeam bridges were extensively studied based on results of maximum Shear Force, maximum Bending moments and maximum deflection values. The conclusive results provide us with the best option, out of the two configurations for the varying spans considered in the study. From the study, T-beam configuration of deck slab proves to be effective than ordinary deck slab supported on girders.
\end{abstract}

Keywords: T-beam bridges, Courbon's method, FEM analysis, Class AA wheeled vehicle.

\section{INTRODUCTION}

A bridge is a structure built to span physical obstacles without closing the way underneath such as a body of water, valley or road. There are different designs of bridges and each have a particular purpose and can be applied to different situations. Designs of bridges vary depending on the function of the bridge, the nature of the terrain where the bridge is to be constructed and anchored, the material used to make it, and the funds available to build it. Bridges are classified on the basis of how shear stresses, compression, tension, and bending moments are distributed in the structure. In our study we are focussing on ordinary two way deck slab supported on girders and T-beam configuration of deck Slab.

\subsection{Ordinary Deck Slab Supported on Girders}

In this configuration,the bridge has five major parts namely Deck slab, longitudinal girders, cross girders and piles/piers (Fig 1). The bridge deck essentially consists of a concrete slab monolithically cast over longitudinal girders so that the T-beam effect prevails. To impart transverse stiffness to the deck, cross girders or diaphragms are provided at regular intervals[5].The load transfer mechanism is similar to any other framed structure with majority of the loads being taken up by the deck slab and then transferred to the substructure comprising the two girders and subsequently the foundation.

\subsection{T-beam Configuration of Deck Slab}

In $\mathrm{T}$-beam configuration the load bearing structure is a single T-shaped cross section (Fig 2). The top of the Tshaped cross section, the flange is the compression member which carries majority of the dead weight and vehicular loads. The web or the vertical section of the beam below the compression flange resists shear stress and provides greater separation for the coupled forces of bending.

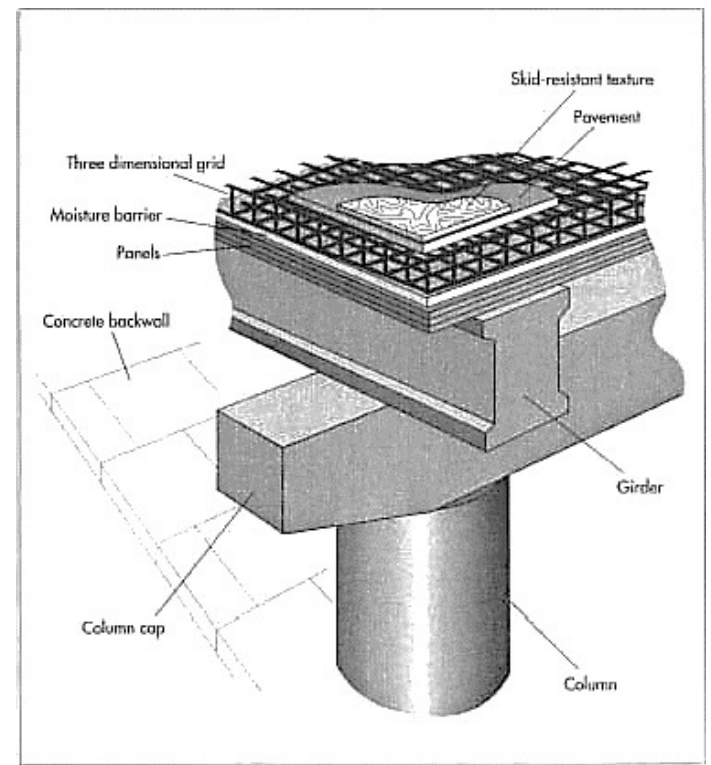

Fig -1: Ordinary deck slab supported on girders 


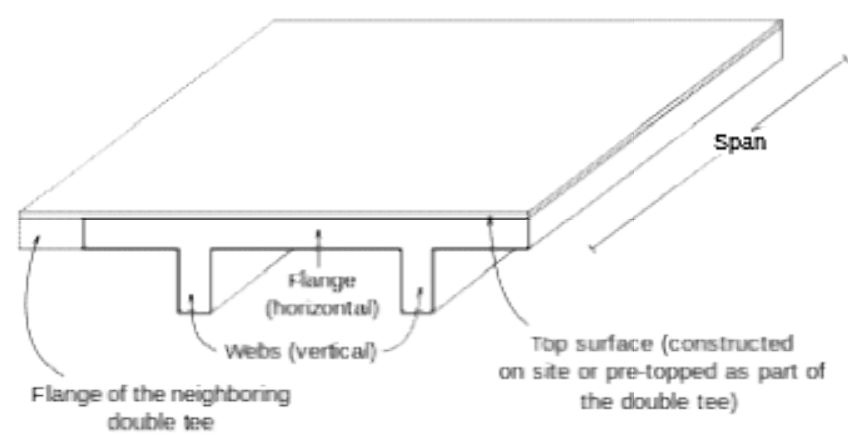

Fig -2: T-beam configuration of deck slab

\subsection{Objective of the Study}

A comparative study of two different configurations of deck slab was performed. They wereordinary deck slab supported on girders and T-Beam configuration of deck slab. The loadings considered for the analysis were IRC Class AA. FEM analysis is done using STAAD Pro. V8i SS6.

In this study, the objectives are achieved by following the underlying sequence:

i. Validating FEM Analysis and comparing it with Conventional Method of analysis for varying span lengths.

ii. Performing FEM Analysis onordinary deck slab supported on girders and T-beam deck slab configuration by considering maximumshear force, maximum bending moment and maximum deflectionas parameters of comparison.

\section{METHODOLOGY}

In this study we followed a particular sequence in which we first fixed the thickness of deck slab to be considered. This was done after analyzing different thickness of deck slab. An equivalent load of $41.42 \mathrm{kN} / \mathrm{m}^{2}$ was applied uniformly of the slab. Based on this study a design thickness of $215 \mathrm{~mm}$ was selected.

This was followed by formulating excel sheets to arrive at results based on conventional design method. Once the values were found to be in accordance we proceeded towards FEM modelling and analysis of the structures. Consequently we conducted FEM analysis on both the configurations under the study and documented the results.

The analysis problems had the following details
i. Varying clear spans - 20m, $24 \mathrm{~m}, 28 \mathrm{~m}$
ii. Width of Roadway- $7.5 \mathrm{~m}$
iii. Spacing between beams- $3 \mathrm{~m}$
iv. Cross Beam Interval- $4 \mathrm{~m}$
v. Thickness of Deck Slab- $215 \mathrm{~mm}$
vi. Grade of concrete is used - M25
vii. Clear cover used- $40 \mathrm{~mm}$
viii. Thickness of wearing course- $75 \mathrm{~mm}$

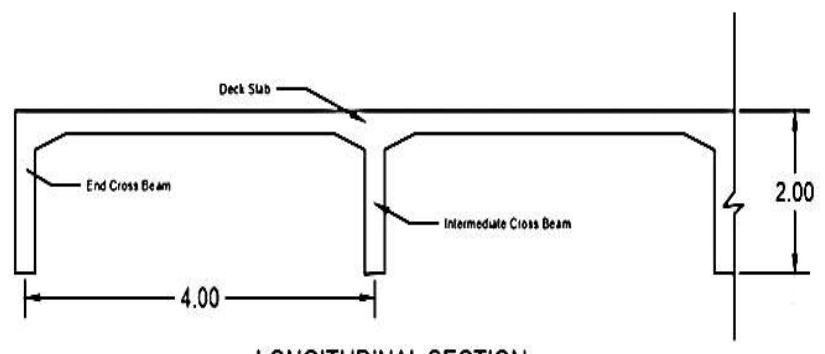

LONGITUDINAL SECTION

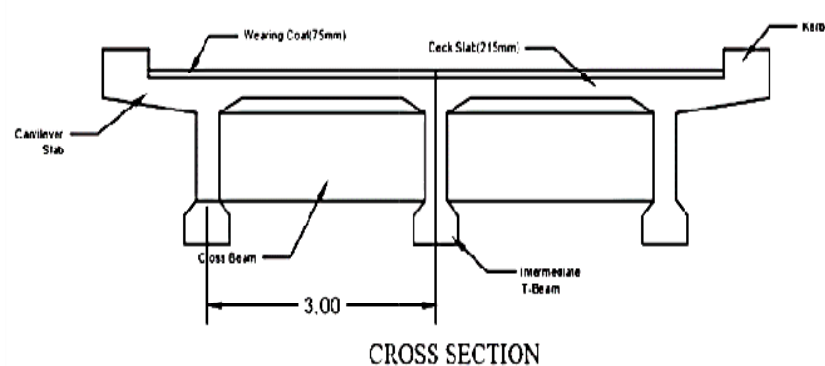

Fig -3: Longitudinal section and cross section of ordinary deck slab configuration.

\subsection{Loading}

\subsubsection{Vehicular Load}

Courbon's Method is popular due to the simplicity of computations as detailed below: When the live loads are positioned nearer to the kerb the centre of gravity of live load acts eccentrically with the centre of gravity of the girder system. Due to this eccentricity, the loads shared by each girder is increased or decreased depending upon the position of the girders.

This is calculated by Courbon's theory by a reaction factor given by,

$$
R_{x}=\left(\frac{\sum W}{n}\right)\left\lceil 1+\left(\frac{\sum I}{\sum d_{x}^{2}} \cdot I\right) d_{x} \cdot e\right\rceil
$$

Where,

$R x=$ Reaction factor for the girder under consideration $\mathrm{I}=$ Moment of Inertia of each longitudinal girder $d x=$ Distance of the girder under consideration from the central axis of the bridge

$\mathrm{W}=$ Total concentrated live load

$\mathrm{n}=$ Number of longitudinal girders

$\mathrm{e}=$ Eccentricity of live load with respect to the axis of the bridge.

\subsubsection{Class AA Wheeled Vehicle Loading}

This loading is a representation of Courbon's method in which a train of class AA vehicles is used as moving point loads on the deck slab. Thus the analysis gives us conditions of the bridge at all the moving interval. 

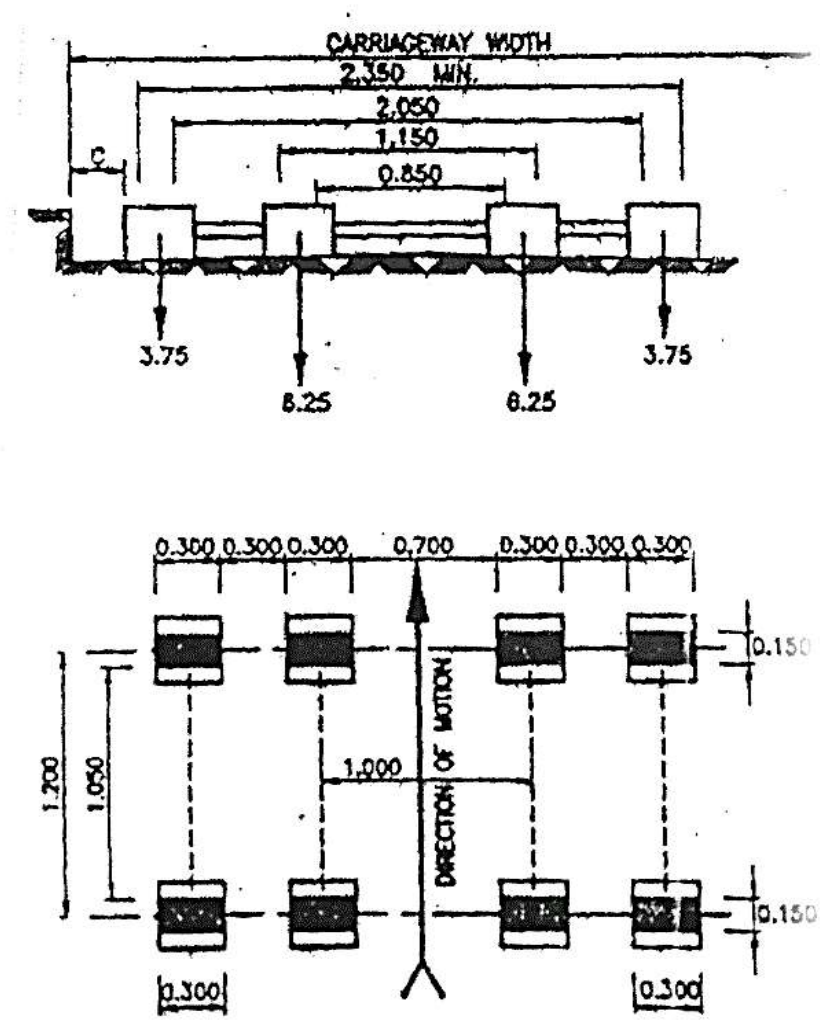

Fig -4: IRC Class AA Wheel loading

\subsection{FEM Analysis}

The FEM analysis was done using Grillage Analogy which models the bridge by converting the deck into a network of rigidly connected beams with discrete nodes. This analysis is in very close agreement with conventional method for small spans. However with increase in spans above $60 \mathrm{~m}$ this method proves to deviate from conventional design.

\subsubsection{Ordinary Deck Slab Supported on Girders}

After obtaining dimensions of girders and slab depth the entire bridge was modelled as one unit. It was subjected to Vehicular loads as per IRC 6-2000.

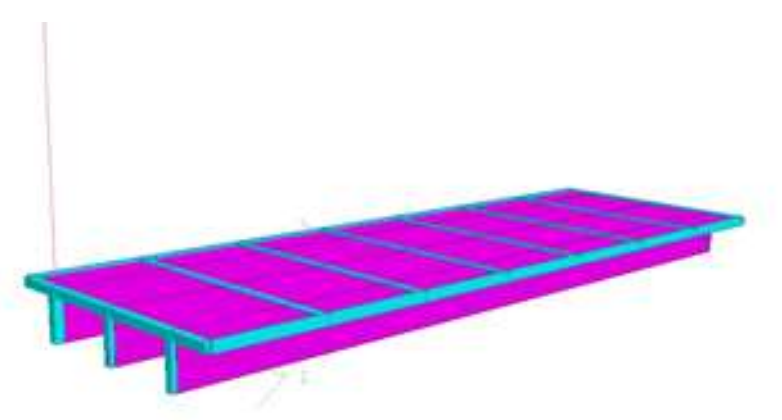

Fig -5: Model of Ordinary Deck slab supported on girders.

\subsubsection{T-beam Deck Slab Configuration}

Three T-beams are considered while modelling the deck slab. The flange depth represents the deck slab and longitudinal girders are represented by the web length.

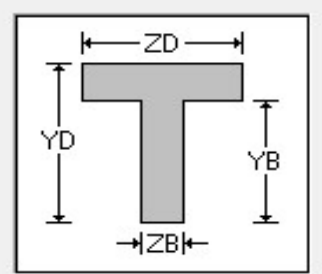

\begin{tabular}{|c|c|}
\hline YD: & 1.9 \\
\hline ZD: & 2.3 \\
\hline YB: & 1.61 \\
\hline$B:$ & 0.3 \\
\hline
\end{tabular}

Fig -6: Cross section of T-beam deck slab configuration.

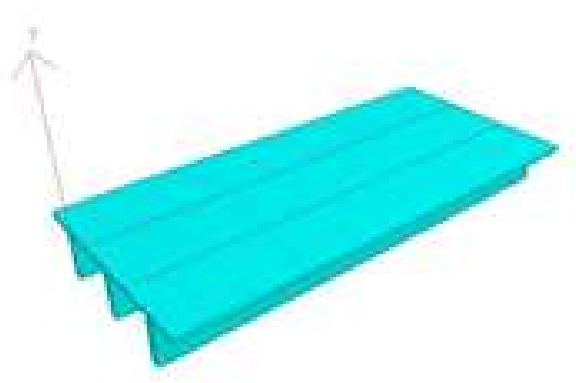

Fig -7: Model of T-beam deck slab configuration.

\section{RESULTS AND DISCUSSIONS}

All the analysis were performedusing STAAD Pro. V8i SS6 with loads taken from Indian Standard codes and particularly Courbon's method was used to come up with class AA wheeled vehicle loading. Validation was done at the start of every analysis procedure using excel sheets and manual calculations.

\subsection{Comparison of Conventional Method and FEM}

\section{Analysis}

The values for bending moment in outer girder obtained from conventional design (excel sheets) were compared with corresponding values obtained from FEM analysis on Ordinary deck slab supported on girders.

Table -1: Maximum Bending moment variation

\begin{tabular}{|l|l|l|l|}
\hline $\begin{array}{l}\text { Span } \\
(\mathrm{m})\end{array}$ & $\begin{array}{l}\text { Conventional } \\
\text { Method }(\mathrm{kN}-\mathrm{m})\end{array}$ & $\begin{array}{l}\text { FEM Analysis } \\
(\mathrm{kN}-\mathrm{m})\end{array}$ & $\begin{array}{l}\text { Percentage } \\
\text { Variation }(\%)\end{array}$ \\
\hline 20 & 1850.16 & 1303.62 & 29.54 \\
\hline 24 & 2240.16 & 1776.11 & 20.72 \\
\hline 28 & 2630.16 & 2320.18 & 11.79 \\
\hline
\end{tabular}

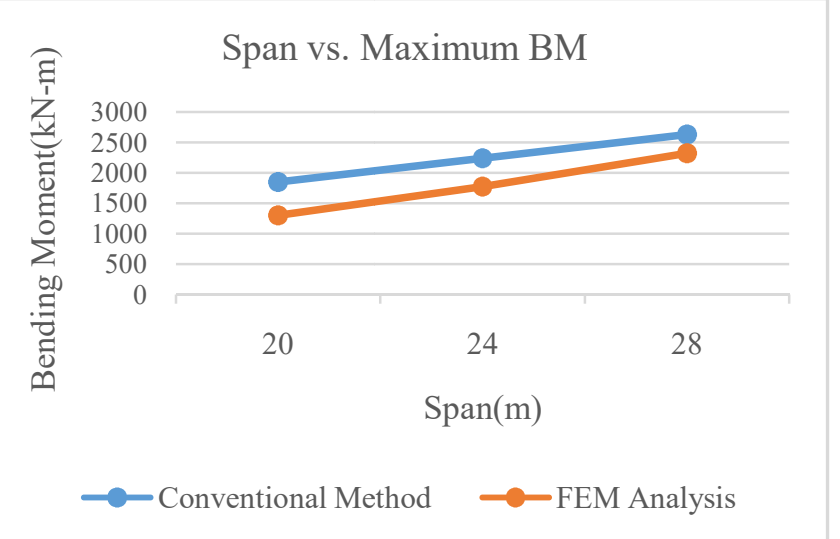

Graph -1: Maximum Bending moment variation for varying span lengths 


\subsection{Comparison of Ordinary Deck Slab Supported} on Girders with T-beam Deck Slab Configuration (FEM Analysis)

\subsubsection{Maximum Bending Moment:}

The maximum Bending Moments occurring in the longitudinal girders in case of ordinary deck slab configuration serve as a reference for comparing with $\mathrm{T}$ beam deck slab configuration.

Table -2: Maximum Bending Moment variation

\begin{tabular}{|l|l|l|l|}
\hline $\begin{array}{l}\text { Span } \\
(\mathrm{m})\end{array}$ & $\begin{array}{l}\text { Ordinary } \\
\text { Deck Slab } \\
(\mathrm{kN}-\mathrm{m})\end{array}$ & $\begin{array}{l}\text { T-beam } \\
\text { Deck Slab } \\
(\mathrm{kN}-\mathrm{m})\end{array}$ & $\begin{array}{l}\text { Percentage } \\
\text { Variation (\%) }\end{array}$ \\
\hline 20 & 3763.50 & 1634.37 & 56.57 \\
\hline 24 & 7137.55 & 2172.40 & 69.50 \\
\hline 28 & 12320.28 & 2918.68 & 76.30 \\
\hline
\end{tabular}

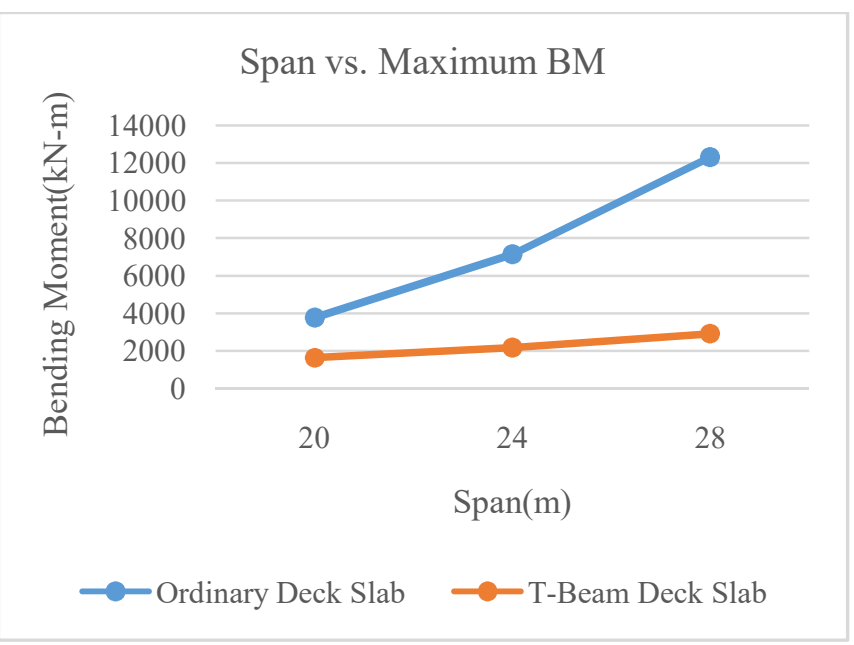

Graph -2: Maximum Bending moment variation of ordinary deck slab and T-beam configuration for varying span lengths.

Percentage variation of maximum Bending Moment values between the two configurations ranges from $50 \%$ to $76 \%$ when comparing ordinary deck slab configuration to the corresponding T-beam configuration.

In the graph it can be seen that in T-beam configuration of deck slab there is very little increase in maximum Bending Moment with span compared to ordinary configuration. The reason being absence of a framed structure. The monolithic deck slab and girder structure thus ensures negligible stress concentrations at joints which leads to little increase in subsequent Bending Moments.

\subsubsection{Maximum Shear Force}

Shear forces play a major role in deciding the type of reinforcement to be used or amount of pre-stress to be induced in order to keep the bridge under serviceable conditions. For this reason the variation in Shear Force was duly noted and studied to aid in deciding the best suited configuration to be used.

Table -3: Maximum Shear Force variation

\begin{tabular}{|l|l|l|l|}
\hline $\begin{array}{l}\text { Span } \\
(\mathrm{m})\end{array}$ & $\begin{array}{l}\text { Ordinary } \\
\text { Deck Slab } \\
(\mathrm{kN})\end{array}$ & $\begin{array}{l}\text { T-Beam } \\
\text { Deck Slab } \\
(\mathrm{kN})\end{array}$ & $\begin{array}{l}\text { Percentage } \\
\text { Variation (\%) }\end{array}$ \\
\hline 20 & 369 & 328.448 & 10.98 \\
\hline 24 & 408 & 380.844 & 6.65 \\
\hline 28 & 446 & 431.996 & 3.10 \\
\hline
\end{tabular}

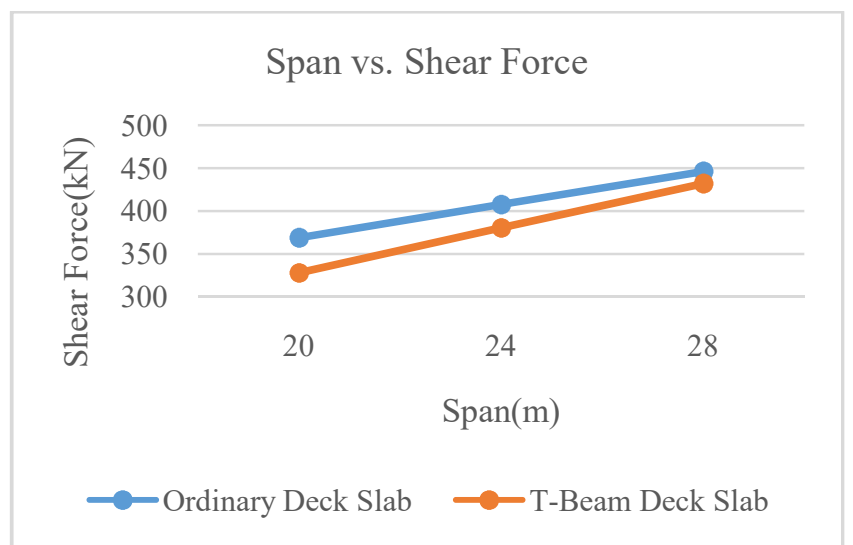

Graph -3: Maximum Shear Force variation of ordinary deck slab and T-beam configuration for varying span lengths.

Shear Force per metre run decreases with increase in spans and the variation ranges from about $3 \%$ to $11 \%$ when ordinary deck slab configuration is compared with T-beam configuration, ordinary deck slab configuration shows higher values of shear force per meter run.

The graph shows that there isn't any significance difference in shear force in both configurations. This is because both configurations have a similar load transfer mechanism and hence the shear forces developed across the surfaces are within a reasonable variation range.

\subsubsection{Deflection}

Since deflection happens to be an important parameter for consideration of serviceability, observations were made to see the variation of deflection with increase in span length for both ordinary deck slab configuration and T-Beam deck slab configuration.

Table -4: Maximum Deflection moment variation

\begin{tabular}{|l|l|l|}
\hline $\begin{array}{l}\text { Span } \\
(\mathrm{m})\end{array}$ & $\begin{array}{l}\text { Ordinary Deck Slab } \\
(\mathrm{m})\end{array}$ & $\begin{array}{l}\text { T-beam } \\
\text { Deck Slab }(\mathrm{m})\end{array}$ \\
\hline 20 & 0.679 & 7.770 \\
\hline 24 & 0.806 & 15.612 \\
\hline 28 & 0.987 & 31.197 \\
\hline
\end{tabular}




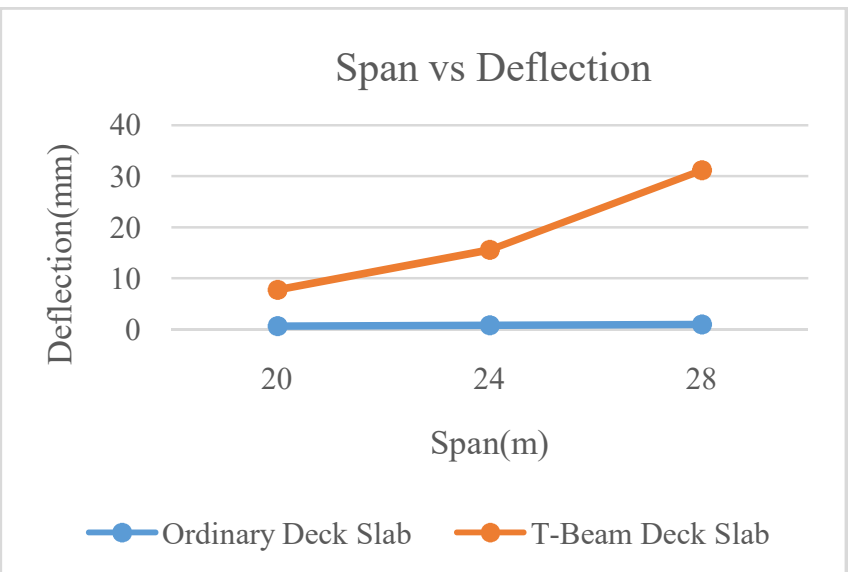

Graph -4: Maximum deflection variation of ordinary deck slab and T-beam configuration for varying span lengths.

Percentage variation of deflection between both the configuration ranges from $91 \%$ to $97 \%$. The drastic increase in values of deflection in T-Beam deck slab with span is attributed to the absence of cross girders which act as shear stress dissipating members in the case of ordinary configuration of deck slab.

The deflection values for T-beam configuration however fall within permissible limits of serviceability in RCC design of bridges of $45 \mathrm{~mm}$ as per IRC. Further verification from American Standards used by Iowa Department of Transportation provides permissible limit of $50 \mathrm{~mm}$.

\section{CONCLUSION}

Hence we can clearly see the effectiveness of using T-beam configuration as it gives us most of the design parameters within permissible limits of serviceability, deflection and shear compared to ordinary deck slab configuration. This is due to the elimination of joints and cross girders that also add to the loadings applied on the bridge.

To obtain even better working results the T-beam configuration deck slab can be subjected to pre/post tensioning. The pre-stressing force can be applied more conveniently and computation of required jacking force is also simple.

This however is not the case in ordinary configuration as we need to come up with a composite design in case prestressing is considered in the design/construction phase.

Ordinary configuration of deck slab also creates long term maintenance and serviceability issues as it has more number of exposed components in the structure. This problem can be overcome with greater ease in case of T-Beam deck slab configuration.

\section{REFERENCES}

[1] Amit Saxena ,Dr. Savita Maru“Comparative study of the analysis and design of T-Beam girders and box girder superstructure"IJREAT International Journal of Research in Engineering \& Advanced Technology, April-May,2013
[2] Hemlatha A , Ashwin K. N , Dattatreya J.K , S.V.Dinesh"Analysis of RC bridge decks for selected national and international standards loading using finite element method" International Journal of Research in Engineering and Technology,Nov-2015

[3] M.G. Kalyanshetti and R.P. Shriram "Study of Effectiveness of Courbon's Theory in the Analysis of T-beam Bridges" International Journal of Scientific \& Engineering Research, Mar-2013

[4] Praful N.K., Balasao Hanumant "Comparative Analysis of T-Beam Bridge by Rational Method And Staad Pro" International Journal of Scientific \&Engineering Research, june-2015

[5] R. Sreedhar, Spurti Mamadapur "Analysis of T-Beam Bridge using fem"International Journal of Engineering and Innovative Technology (IJEIT), Sep-2012

[6] Supriya Madda, Kalyanshetti M.G.'Dynamic Analysis of T-Beam Bridge superstructure"International Journal of Civil and Structural Engineering, 2013

[7] IRC 6 - 2000, "Standard Specifications and Code of Practice for Road Bridges". The Indian Road Congress, New Delhi.

[8] IS 456 - 2000, "Indian Standard Plain and Reinforced Concrete- Code of Practice". Bureau of Indian Standards, New Delhi.

\section{BIOGRAPHIES}

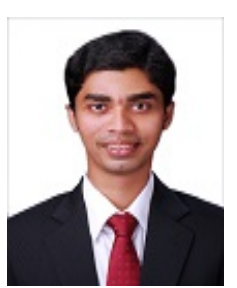

Sandesh Upadhyaya K. completed his B.E. in Civil engineering from M.C.E., Hassan. M.Tech. in Structural Engineering from M.I.T. Manipal. He is currently working as Assistant Professor in the Department of Civil Engineering Manipal Institute of Technology, Manipal.

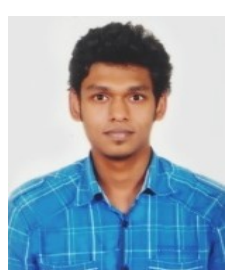

F. Sahaya Sachin is an under graduate student pursuing his Bachelors of Technology in Civil Engineering, Manipal Institute of Technology, Manipal. 